
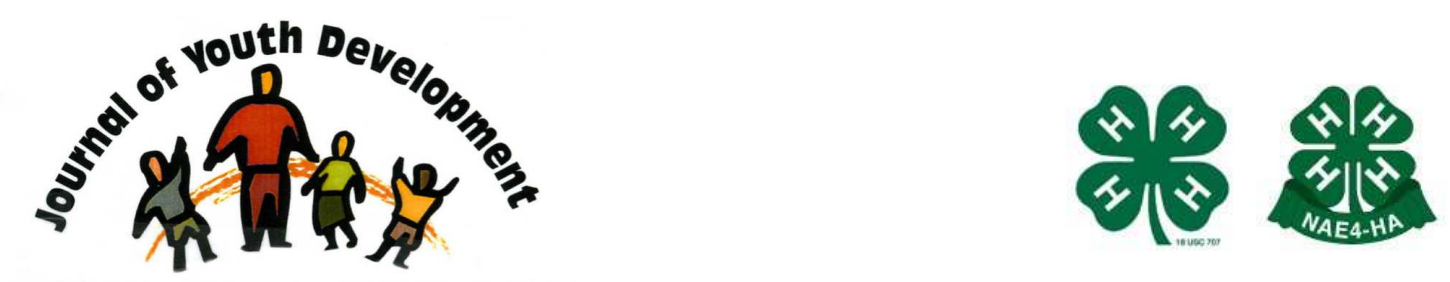

Bridging Research \& Practice

\title{
YA4-H! Youth Advocates for Health: Teens as Teachers
}

\author{
Jeffrey M. Flesch \\ College of Public Health and Human Sciences \\ Oregon State University \\ Corvallis, OR \\ fleschj@onid.orst.edu \\ Joy R. Lile \\ College of Public Health and Human Sciences \\ Oregon State University \\ Corvallis, OR \\ lilejo@onid.orst.edu \\ Mary E. Arnold \\ College of Public Health and Human Sciences \\ Oregon State University \\ Corvallis, OR \\ mary.arnold@oregonstate.edu
}




\title{
JOURNAL OF YOUTH DEVELOPMENT \\ bridging research and practice

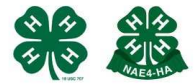

Volume 10, Number 2, Summer 2015

Article 151002RR001

\section{YA4-H! Youth Advocates for Health: Teens as Teachers}

\author{
Jeffrey M. Flesch, Joy R. Lile and Mary E. Arnold \\ Oregon State University
}

\begin{abstract}
Although the research literature speaks to the necessity of having a high-quality training curriculum for teens as teachers (TAT) programs, there are very few TAT training curricula available to practitioners. This review provides practitioners with a preview of the Youth Advocates for Health (YA4-H!) TAT training curriculum. The YA4-H! TAT training curriculum exposes teens to several domains necessary to teach younger youth effectively, such as getting to know their audience, preparing to teach, teaching tips and tools, reflection and evaluation time, and recruitment strategies to help practitioners select youth to teach. Drawing from published research including Lee and Murdock's (2001) work on best practices for preparing teen teachers to teach, this review presents an overview of the lesson categories included in the YA4-H! TAT training curriculum.
\end{abstract}

\section{Resource Review}

The YA4-H! Youth Advocates for Health (YA4-H!) Teens as Teachers (TAT) training curriculum is designed to help facilitate trainings in which teens learn to teach health-related information to younger children. Lee and Murdock (2001) cite 10 essential elements that need to be incorporated into a successful TAT program, which cover all aspects of program design from staff selection and curriculum creation through teen recruitment, training, and ongoing support. The YA4-H! TAT training curriculum aligns with this research by thoroughly addressing each of these elements. Because the curriculum is not tied to a specific program it is also highly portable, which allows practitioners the ability to integrate it into existing health-related youth programs. The YA4-H! TAT curriculum is grounded in positive youth development and creates opportunities for teens to learn about the participant audience, prepare to teach, learn teaching tips and tools, and reflect on and evaluate themselves and the program. The YA4-H! Teens as Teachers curriculum was piloted in two states, and is reviewed and recommended by the National 4-H curriculum jury. 


\section{Getting to Know Your Audience}

The Getting to Know your Audience section of the curriculum creates opportunities for teens to learn about teaching younger children, including child development and learning styles.

Teaching teen teachers about the ages and stages of child development helps prepare them to interact with and teach youth with varying developmental needs, and covering diverse learning styles helps them integrate different approaches into their teaching. This section also provides lessons on cultural diversity and cultural identity, which can help teens build their awareness while also increasing their knowledge base to become more effective teachers.

\section{Preparing to Teach}

The Preparing to Teach section of the curriculum includes opportunities for teens to practice fun and engaging teaching skills. Teens learn about critical facilitation skills, professionalism, and how to be a mentor to younger children. Practicing facilitation skills helps teens keep younger children engaged in the lesson delivery by building trust, cooperation, and support. Teens also learn about presenting themselves in a professional manner, which includes dressing for success. Finally, teens learn how to become a mentor to younger children. Learning about facilitation skills, professionalism, and mentoring provides skills that teens can use today and in the future. Incorporating these skills into their teaching persona helps teens increase their confidence within professional contexts.

\section{Teaching Tips and Tools}

Providing teens with practical tips and tools can help them build capacities and confidence, which can increase their efficacy as teachers. The Teaching Tips and Tools section of the curriculum teaches teens how to keep a group on task, set up an effective and fun classroom environment, and be explicit when interacting with younger youth. In addition, teens get the practice by teaching each other. By providing and demonstrating experiential learning, the training encourages teens to use these practices in their own teaching.

\section{Reflection and Evaluation}

Allowing space for teen teachers to have quality time for reflection helps teens build their awareness of their personal strengths and challenges as a teacher. It also builds teens' evaluative skills and enhances their contribution to the program processes. Reflection and evaluation time also serve to integrate teens' ideas about how to improve the program. Providing time for teens to share their learning and suggestions for improving the program creates a better-rounded and engaging teaching context while also fostering more engaged, excited, and energetic teachers (Lee, \& Murdock, 2001).

\section{Recruitment Materials}

Intentionally is vital when selecting and recruiting teen teachers (Lee, \& Murdock, 2001). As such, this curriculum provides practitioners with ideas on how to market, advertise, select and recruit teens. Sample recruiting materials including a sample flyer, press release, letter to schools, job description, application, agreement form, and a training and readiness tracking form are provided in the training curriculum. 
Each of the YA4-H! training curriculum sections also include handouts that are designed to be used in conjunction with the training agendas. The handouts are geared to teens and work to make the learning process fun and engaging.

\section{Final Thoughts}

TAT programs for youth development are gaining popularity, and although the literature speaks to the necessity of high-quality training curricula for teen teachers (Lee, \& Murdock, 2001; Ripberger, Devitt, \& Gore, 2009; Story, Lytle, Birnbaum, \& Perry, 2002), there are few curricula available to prepare teens to teach. The YA4-H! curriculum fills this important gap. The inclusion of experiential learning within the YA4-H! TAT training creates a curriculum that is engaging and fun to teach. Providing the opportunity for teens to develop personally and professionally within a fun context is an important first step to creating high quality TAT programs for teen teachers and youth participants.

\section{Ordering Information}

YA4-H! Youth Advocates for Health: Teens as Teachers. Anticipated publication is July, 2015. The curriculum will be available for purchase from the National 4-H Mall. Please contact Mary Arnold at mary.arnold@oregonstate.edu for more information.

\section{References}

Lee, F.C., \& Murdock, S. (2001). Teenagers as teachers programs: Ten essential elements. Journal of Extension [On-line], 39(1). Available at: http://www.joe.org/joe/2001february/rb1.php

Ripberger, C., Devitt, A., \& Gore, S. (2009). Training teenagers as food and fitness ambassadors for out-of-school programs. Journal of Extension [On-line], 475), 1-5. Available at: http://www.joe.org/joe/2009october/iw5.php

Story, M., Lytle, L.A., Birnbaum, A.S., \& Perry, C.L. (2002). Peer-led, School-based nutrition education for young adolescents: Feasibility and process evaluation of the TEENS Study. Journal of School Health, 72(3), 121-127.

(C) Copyright of Journal of Youth Development Bridging Research and Practice. Content may not be copied or emailed to multiple sites or posted to a listserv without copyright holder's express written permission. Contact Editor at: patricia.dawson@oregonstate.edu for details. However, users may print, download or email articles for individual use.

ISSN 2325-4009 (Print); ISSN 2325-4017 (Online) 